\title{
Nutritional status and market activities of female traders in a major City South East, Nigeria
}

\author{
Ukegbu $\mathrm{PO}^{1 *}$, Uwaegbute $\mathrm{AC}^{1}$, Emezue $\mathrm{AG}^{1}$ \\ ${ }^{1}$ Dept of Human Nutrition and Dietetics, Michael Okpara University of Agriculture, Umudike, \\ PMB 7267, Umuabia Abia State, Nigeria
}

\begin{abstract}
Background: The market place as an occupational environment can predispose individuals to obesity, mainly due to the sedentary nature and enhanced access to food. Information on the nutritional status of market women is scarce in Nigeria Methods: The cross-sectional study was undertaken at Umuahia main market and involved 240 women. By using a questionnaire socio-demographic characteristics and market activities of respondents were recorded. Anthropometric measurements were used to assess the Body Mass index (BMI) and waist hip circumference ratio (WHR). Food frequency questionnaire was used to obtain information on the frequency of consumption of foods. Data were analyzed using descriptive statistics and Pearson correlation coefficient. Results: One third $(36.7 \%)$ of the women went to the market six times a week. Market activities of $40 \%$ of the women mainly involved sitting and selling their wares. Green leafy vegetables (41.52\%), baked products $(40.36 \%)$ and roots/tubers $(38.33 \%)$ were the main food groups consumed at least twice a week. BMI classification showed that $25 \%$ and $31.7 \%$ were overweight and obese, respectively. There was a weak but significant correlation between BMI and snack consumption $(\mathrm{r}=0.3313 ; \mathrm{p}<0.05)$. Conclusion: Prevalence of obesity was high. Awareness campaigns on need for regular exercise should be emphasized in market places.
\end{abstract}

Key words: Nutritional status, market activities, dietary habits, BMI, women,

\section{Introduction}

Women are responsible for generating food security for their family members in developing countries (Akinloye, 2010). A review of reports on women in sub Saharan Africa revealed that their role in both subsistence food production and food preparation may give them more control over their own and children's dietary consumption than in some other regions of the world, however, this comes at the cost of extremely long and energy demanding work days (Harrison et al., 1985; FAO/WHO, 1992; World Bank, 1992).

Women constitute the greatest percentage of traders found in various markets where they stay from dawn to dusk. Their dietary habits may lead to poor and even dangerous lifestyle. Their market activities may influence lifestyle or determine the lifestyle which may eventually affect their nutritional status. The market place is an occupational environment that can predispose individuals to obesity, mainly due to the sedentary nature and enhanced access to food (Afolabi et al., 2004). Market men and women spend most hours of the day sitting down and involve in many other sedentary activities and consume diets with mean daily energy intake higher than recommended levels (Afolabi et al., 2004). These conditions increase their risk of developing obesity and other non-communicable diseases. A study of traders across various parts of Nigeria revealed prevalence of obesity to be $16.3 \%$ in Ibadan (Balogun and Owoaje, 2007), 12.3\% in Lagos (Odugbemi et al., 2012) and $28.1 \%$ in Sokoto (Awosan et al., 2014). There is, however, dearth of information on abdominal obesity and market activities of female traders. This study will therefore assess the dietary habits, market activities and nutritional status of female traders. It is believed that this would in turn provide a foundation for designing interventions that would be effective in improving their nutritional situation.

\section{Methods}

\section{Area of study}

The study was carried out at Umuahia main market in Umuahia North Local Government Area (LGA) of Abia State, Nigeria. Umuahia main market is bordered by two major towns Ibeku and Ohuhu.

*Corresponding author: ukegbu.patricia@mouau.edu.ng 


\section{Study design}

The study was a cross-sectional survey of market women in Umuahia main market carried out between June and July, 2012.

\section{Sample size determination}

A sample size of 240 was calculated using the formula: $\mathrm{n}=\mathrm{Z}^{2} \mathrm{P}(100-\mathrm{P}) / \mathrm{X}^{2}$ (Araoye, 2003), where $\mathrm{Z}$ represents $95 \%$ confidence interval taken to be $1.96, \mathrm{X}$ is $5 \%$ margin of error and $\mathrm{P}$ is estimated prevalence of obesity (16.3\%) among female traders in Nigeria (Balogun and Owoaje, 2007).

\section{Sampling technique}

Multi-stage sampling was employed in selecting the women. The market was stratified into three different sections comprising of those at "Isi" gate (i.e. those who do not have shops but stay under an umbrella cover), those who stay inside the market with small stalls/ shops and those at good-shed with comfortable shops). From the three different sections, systematic sampling was employed in selecting 40 women from each of the sections. A sampling interval of three was chosen and the first trader was selected between 1 and 3, thereafter, every $3^{\text {rd }}$ trader was subsequently selected until the required sample size was obtained.

\section{Data collection}

Two research assistants were trained in questionnaire administration and instrumentation techniques. Validation of the questionnaire was done by lecturers in the Department of Human Nutrition and Dietetics, Michael Okpara University of Agriculture, Umudike. Corrections and suggestions were incorporated to produce the final draft of the questionnaire. Pre-test was carried out using a group of market women in Ohokobe market in the same local government but these were not used in the final data analysis. The questionnaire was used to collect information on socio-demographic characteristics, market activities, dietary habits and food consumption pattern.

\section{Anthropometric measurements}

Anthropometric measurements of weight and height were taken and these were used to calculate the Body Mass Index (BMI). Weight was measured using a bathroom scale (HANSON model) which was adjusted to zero before each measurement was taken. The respondents stood without shoes and with their hands resting by their sides and readings were taken to the nearest 0.1 kilogram. Height was measured using a calibrated heightometer.
The respondents stood straight without shoes on a flat surface, with their head straight and height readings were taken to the nearest 0.1 meter. The measurements were taken in duplicates using standard procedures and the averages were used (WHO, 1995).

The Body Mass index (BMI) and waist hip ratio (WHR) were used as indicators of nutritional status. BMI was calculated as body weight $(\mathrm{kg})$ divided by height $\left(\mathrm{m}^{2}\right)$ and women were classified as normal (BMI $<18.49 \mathrm{~kg}$ / $\mathrm{m} 2)$, overweight $\left(\mathrm{BMI}=18.50-24.99 \mathrm{~kg} / \mathrm{m}^{2}\right)$ and obese $\left(\mathrm{BMI}>25 \mathrm{~kg} / \mathrm{m}^{2}\right.$ ) using WHO standards (WHO, 2000). Waist and hip circumferences were measured and used for the calculation of waist-hip ratio (WHR). Waist circumference was measured using a non-stretchable tape placed between the lower rib margin and iliac crest, while hip circumference was taken by placing the tape firmly around the hip at the point of the greatest circumference and measurement was taken to the nearest $0.1 \mathrm{~cm}$. Waisthip ratio (WHR) was calculated by dividing the waist by the hip circumference (WHO, 1995). WHR was defined as "at risk" if it was $>0.85$ for females (WHO, 2000).

\section{Food consumption pattern}

A previously validated food frequency questionnaire (FFQ) (Ukegbu, 2014) was used to estimate the frequency of consumption of common foods. The respondents were asked to report the types of foods consumed and frequency of consumption (daily, weekly etc).

\section{Statistical analysis}

Data were analysed using SPSS version 15.0. Results were presented as frequencies and percentages. Pearson correlation analysis was used to determine the relationship between the nutritional status of the market women (BMI) and their dietary habits. A p-value of less than 0.05 was regarded as statistically significant.

\section{Results}

\section{Socio-demographic characteristics}

Table 1 revealed that most $(28.3 \%)$ of the market women were within the age group of 30-39 years, majority were married $(65 \%)$, while over half $(55.0 \%)$ were residing in the urban areas. About $91.7 \%$ were educated with secondary school holders having the highest percentage (46.7\%), while $8.3 \%$ had no formal education (Table 1$)$. 
Table 1. Socio-demographic characteristics of the market women

\begin{tabular}{lll}
\hline Parameters & Frequencies & Percentages \\
\hline Age (years) & 52 & 21.7 \\
$<30$ & 68 & 28.3 \\
$30-39$ & 48 & 20.0 \\
$40-49$ & 72 & 30.0 \\
$>50$ & & \\
Marital status & 156 & 65.0 \\
Married & 36 & 15.0 \\
Single & 36 & 15.0 \\
Widowed & 12 & 5.0 \\
Divorced & \\
Place of residence & 132 & 55.0 \\
Urban & 108 & 45.0 \\
Rural & \\
Level of education & & 8.3 \\
None & 20 & 31.7 \\
Primary & 76 & 46.7 \\
Secondary & 112 & 13.3 \\
Tertiary & 32 & \\
\hline
\end{tabular}

Distribution of the market women according to their market/physical activities

Most of the women (55\%) wake up before 6.00am daily, while the rest (45\%) wake up after 6.00am daily as shown in Table 2. The resumption time in the market for about half $(55 \%)$ of the women was between $6.31-7.00 \mathrm{am}$ daily. About half $(56.7 \%)$ of the market women leave the market between $5.00-6.00 \mathrm{pm}$ daily, while $33.3 \%$ leave after $6.00 \mathrm{pm}$. Most of them $(36.7 \%)$ went to the market six times a week, while the rest went between zero to five times per week (53.3\%). Majority (60\%) spent between 3-6 hours of their time sitting and selling their wares, on the other hand, $63.3 \%$ noted they spent 3-6 hours walking around in the market (Table 2).

\section{Dietary habits of the market women}

Dietary habits of the market women revealed that most of the women $(62.5 \%)$ usually miss their breakfast while more than half $(58.3 \%)$ missed meals due to lack of time to cook. The commonly consumed snacks were meat pie/biscuits (36.7\%) and cakes (27.5\%). More than half $(57.9 \%)$ took one form of alcoholic beverage at least twice a week, while none of the respondents smoked (Table 3).
Table 2. Distribution of the women according to their market activities

\begin{tabular}{|c|c|c|}
\hline Options & $\mathbf{n}$ & $\%$ \\
\hline \multicolumn{3}{|c|}{ Wake up time by the women } \\
\hline Before $6 \mathrm{am}$ & 132 & 55.0 \\
\hline $6.00-6.30 \mathrm{am}$ & 60 & 25.0 \\
\hline $6.31-7.00 \mathrm{am}$ & 36 & 15.0 \\
\hline $7.01-7.30 \mathrm{am}$ & 8 & 3.3 \\
\hline 7.31-8.00am & 4 & 1.7 \\
\hline After $8.00 \mathrm{am}$ & 0 & 0.0 \\
\hline \multicolumn{3}{|c|}{ Resumption time in the market place } \\
\hline Before $6 \mathrm{am}$ & 20 & 8.3 \\
\hline $6.00-6.30 \mathrm{am}$ & 40 & 16.7 \\
\hline $6.31-7.00 \mathrm{am}$ & 132 & 55.0 \\
\hline $7.01-7.30 \mathrm{am}$ & 48 & 20.0 \\
\hline 7.31-8.00am & 0 & 0.0 \\
\hline After 8.00am & 20 & 8.3 \\
\hline \multicolumn{3}{|c|}{ Time they leave the market } \\
\hline 12 noon- $1.00 \mathrm{pm}$ & 4 & 1.7 \\
\hline $1.01-2.00 \mathrm{pm}$ & 0 & 0.0 \\
\hline $2.01-3.00 \mathrm{pm}$ & 0 & 0.0 \\
\hline $3.01-4.00 \mathrm{pm}$ & 20 & 8.3 \\
\hline $4.01-5.00 \mathrm{pm}$ & 24 & 10.0 \\
\hline $5.01-6.00 \mathrm{pm}$ & 112 & 46.7 \\
\hline After $6.00 \mathrm{pm}$ & 80 & 33.3 \\
\hline \multicolumn{3}{|c|}{ Number of days they go to the market } \\
\hline Once & 0 & 0.0 \\
\hline$>3$ & 20 & 8.3 \\
\hline 4 & 84 & 35.0 \\
\hline 5 & 24 & 10.0 \\
\hline 6 & 88 & 36.7 \\
\hline 7 & 24 & 10.0 \\
\hline \multicolumn{3}{|c|}{ Time spent sitting in the market } \\
\hline 3-6 hours & 144 & 60.0 \\
\hline 7-12hours & 68 & 28.3 \\
\hline Not sure & 28 & 11.7 \\
\hline \multicolumn{3}{|c|}{ Time spent walking around in the market } \\
\hline 3-6hrs & 76 & 63.3 \\
\hline 6.1-12hrs & 36 & 30.0 \\
\hline Not sure & 8 & 6.7 \\
\hline
\end{tabular}

Table 3. Dietary habits of the market women

\begin{tabular}{|c|c|c|}
\hline Variables & $\mathbf{n}$ & $\%$ \\
\hline \multicolumn{3}{|l|}{ Meals usually missed } \\
\hline Breakfast & 150 & 62.5 \\
\hline Lunch & 62 & 25.8 \\
\hline Dinner & 28 & 11.7 \\
\hline \multicolumn{3}{|l|}{ Reason for missing meals } \\
\hline No time to cook or eat it & 140 & 58.3 \\
\hline Don't like taking the meal & 28 & 11.7 \\
\hline To maintain my figure & 24 & 10.0 \\
\hline Habit formed & 24 & 10.0 \\
\hline Makes me lazy for the day & 24 & 10.0 \\
\hline \multicolumn{3}{|l|}{ Snacks eaten while in the market } \\
\hline Cakes & 66 & 27.5 \\
\hline Meat pie/biscuits & 88 & 36.7 \\
\hline Moimoi/akara & 48 & 20.0 \\
\hline Groundnut & 10 & 4.2 \\
\hline & 28 & 11.7 \\
\hline \multicolumn{3}{|l|}{$\begin{array}{l}\text { Alcohol consumed at least twice a } \\
\text { week }\end{array}$} \\
\hline Stout & 100 & 41.7 \\
\hline Other beers & 24 & 16.2 \\
\hline None & 116 & 48.3 \\
\hline \multicolumn{3}{|l|}{ Smoking } \\
\hline Yes & 0 & 0.0 \\
\hline No & 120 & 100.0 \\
\hline
\end{tabular}




\section{Anthropometric characteristics of the market women}

Table 4 shows that the prevalence of overweight and obesity were $25 \%$ and $31.7 \%$, respectively. Using WHR classification, about two-thirds $(75.8 \%)$ were at risk of abdominal fat accumulation. Correlation analysis revealed that there was a weak but significant correlation between BMI and snack consumption $(r=0.3313$; $\mathrm{p}<0.05)$.

Table 4. Anthropometric indices of the market women

\begin{tabular}{lll}
\hline Parameter & n & \% \\
\hline BMI & & \\
Normal $\left(18.50-24.99 \mathrm{~kg} / \mathrm{m}^{2}\right)$ & 104 & 43.3 \\
Overweight $\left(25.00-29.99 \mathrm{~kg} / \mathrm{m}^{2}\right)$ & 60 & 25.0 \\
Obese $\left(>30 \mathrm{~kg} / \mathrm{m}^{2}\right)$ & 76 & 31.7 \\
WHR & & \\
Safe level $(<0.85)$ & 58 & 24.2 \\
At risk $(>0.85)$ & 182 & 75.8 \\
\hline
\end{tabular}

$\mathrm{BMI}=$ Body Mass Index, $\mathrm{WHR}=$ Waist-hip ratio

\section{Food consumption pattern}

The frequency of consumption of different food groups showed that the women consumed foods rich in roots and tubers twice a week $(38.3 \%)$ followed by daily consumption $(20.84 \%)$. The highest percentage $(36.0 \%)$ rarely consumed legumes while 34.67\% consumed them twice a week. More than one third (36.1\% and $35.6 \%$ ) consumed starchy fruits twice a week and rarely, respectively. Cereals were rarely $(42.7 \%)$ consumed while $28.3 \%, 14.2 \%$ and $14.8 \%$ consumed them twice a week, daily and thrice a week, respectively. Green leafy vegetables were mainly consumed twice a week and daily by $41.5 \%$ and $21.1 \%$, respectively by the women. Consumption of meat, poultry and fish products was 31.5\%, 39.7\%, $15.5 \%$ and $13.3 \%$ for twice a week, rarely, daily and thrice a week, respectively. Baked products were consumed twice a week $(40.4 \%)$ and daily $(22.4 \%)$ by the women. Milk and dairy products were commonly consumed twice week $(32.9 \%), 28.1 \%$ rarely consumed it while $24.8 \%$ and $14.2 \%$ consumed it daily and thrice a week, respectively. Consumption of fat and oil products was mainly twice a week $(33.9 \%)$ and daily $(25.8 \%)$. Others rarely consumed it $(22.5 \%)$ or did thrice a week $(17.8 \%)$.

Table 5. Food consumption pattern of the market women

\begin{tabular}{lllll}
\hline Food type & Daily (\%) & Twice a week (\%) & Thrice a week (\%) & Rarely (\%) \\
\hline Roots and tubers (eg & $50(20.8)$ & $92(38.3)$ & $223(9.4)$ & $75(31.5)$ \\
Legumes & $40(16.7)$ & $83(34.7)$ & $30(12.7)$ & $87(36.0)$ \\
Starchy fruits & $29(12.2)$ & $87(36.1)$ & $39(16.1)$ & $85(35.6)$ \\
Cereals & $34(14.2)$ & $68(28.3)$ & $35(14.8)$ & $103(42.7)$ \\
Green leafy vegetables & $50(21.1)$ & $100(41.5)$ & $42(17.6)$ & $48(19.9)$ \\
Fruits & $34(14.3)$ & $69(28.8)$ & $42(17.4)$ & $95(39.6)$ \\
Meat, poultry and fish & $37(15.5)$ & $76(31.5)$ & $32(13.3)$ & $95(39.7)$ \\
Baked products & $54(22.4)$ & $97(40.4)$ & $46(19.4)$ & $43(17.9)$ \\
Milk and dairy products & $59(24.8)$ & $81(32.9)$ & $43(14.2)$ & $68(28.1)$ \\
Fats and oils & $62(25.8)$ & & & $54(22.5)$ \\
\hline
\end{tabular}

\section{Discussion}

The result of this study showed that half of the respondents were within the reproductive age with the range of less than 40 years and were married. Majority of the respondents $(90 \%)$ had one form of education or the other with secondary education accounting for a higher proportion. The level of secondary education reported in this study is similar to 38\% reported among a group of market women in Ikosi-isheri, Lagos state (Akinloye, 2010).

The market activities revealed the women woke up quite early (before 6.00am) to prepare for the market. The early wake up time of these traders may not be unconnected with the fact that they have to prepare their children for school and probably prepare meals for them. Most of the respondents go to the market up to six times in a week. The frequency of going to the market indicated that the women were full time traders whose livelihoods probably depended on the proceeds from their sales. The implication of this is that the better part of the whole day is spent in the market place while family activities are minimized. Market activities for majority (60\%) of the women involved sitting for up to six hours a day. Although, some equally reported walking around in the market, there is however a possibility that the women may have overestimated their walking activities. This is because the market in question is not a very large one 
coupled with the fact that the respondents sampled were mainly those that had shops, stalls or sold by the roadside with their umbrella and not necessarily hawkers. Again, walking activities of the women may not necessarily be in the form of vigorous physical activity that could lead to weight loss. The fact that most of the respondents perceived their activity level and market activities to be physically active and very stressful might be linked to either ineffective management of time or lack of sleep during the day (siesta) .

The meal usually missed by most of the respondents was breakfast and the main reason for skipping it was due to lack of time to either prepare or eat the meal. The role of women in carrying out household chores coupled with their income generating activities may point to the fact that they may not have the time for food preparation early in the morning. Even when they do prepare the meals, their busy schedule may not allow them partake of such meals. Ming et al. (2006) noted that breakfast is the most important meal of the day that replenishes the body and brain after a night's fast. Skipping of breakfast by the women may mean that they may tend to over eat at the next meal and this might make them add weight coupled with their sedentary lifestyle. Consumption of snacks, baked products and fat and oil was on the high side as many of them consumed one form of high fat dense snack or the other on a daily basis. This could be due to its ready availability in the market. Market women while waiting for their customers may want to take snacks in between meals either to satisfy their appetite or enjoyment for food. Consumption of snacks high in saturated fat could lead to deposition of dietary fat in the fat stores of the adipose tissues and thus increase the chances of an individual getting over weight or obese. The relationship between BMI and snack consumption corroborates reports of other authors (Poulain, 2002; Piernas and Popkin, 2010) which found that frequent consumption of snacks is strongly associated with the rising rates of obesity. Similarly, WHO (2010) noted that people may become overweight or obese due increased consumption of foods which contain high levels of sugar and fat. From the food consumption pattern (Table 5), most of the foods in the food groups were consumed more twice a week. The high rate of consumption of green leafy vegetables could be attributed to the availability of fresh green vegetable during the rainy season when this study was conducted between (June and July, 2012). Similarly, the high consumption could be attributed to the fact that the West African diet consists mainly of mixed dishes of green leafy vegetables served as accompaniment to cereals, root and tuber staples (Oniang'o et al., 2003). Consumption of fruits was rather low in this study. This corroborates results of Ganasegeran et al. (2012) which reported that most of their respondents consumed fruits less than three times a week. As pointed out (Oniang'o et al., 2003), low consumption of fruits among Africans from infancy to adulthood could be attributed to factors such as income, educational level, place of residence (rural or urban), ignorance and seasonality. Alcohol consumption was high as most of the market women noted they consumed the brand "stout". Too much consumption of alcohol is a predisposing factor to obesity and can as well lead to a cluster of other cardiovascular diseases.

Based on BMI classification, the prevalence of overweight and obesity combined was $56.6 \%$ (25\% and $31.7 \%$, respectively). The high rate of overweight and obesity maybe a reflection of the sedentary lifestyle of the market women since the better part of their day was made up of sitting activities. The rate of obesity reported in this study was lower than 69\% reported among a group of market women in Abeokuta (Mebude, 2010), but higher than $16.3 \%$ reported among female traders in Ibadan (Balogun and Owoaje, 2007. The differences in rates may be related to differences in genetic make up and socioeconomic status of the three different groups of market women. The high prevalence of overweight and obesity among female traders in this study could also be attributed to cultural norms in Africa where being fat is associated with affluence, beauty and healthy living (Okafor et al., 2015). Ojo et al. (2011) reported that waist size reflects growing evidence of visceral fat surrounding the abdominal organs and also increases the rate of heart diseases. Using WHR classification, more than half $(75.8 \%)$ was at risk of abdominal fat accumulation. Oladoyinbo et al. (2015) in a study of traders in South west Nigeria reported a prevalence of $83.9 \%$ for abdominal obesity among female traders. This study has limitations in that the sample size was relatively small and only one major market in Umuahia metropolis was sampled. Therefore, other major markets in the state need to be sampled to provide more information on the nutritional status and market activities of female traders. Due to dearth of information on abdominal obesity among market traders, it was difficult to make further comparisons regarding abdominal obesity.

\section{Conclusion}

The rate of overweight and obesity were high. The market and lifestyle activities could be regarded as sedentary. The study underscores the need for educational campaigns regarding healthier lifestyles, diversification of diet, weight management and control to be conducted regularly in various markets. 


\section{Acknowledgement}

The authors are grateful to the research assistants who assisted in data collection and the women who willingly participated in the study.

\section{Conflict of interest}

There is no conflict of interest.

\section{References}

Afolabi, W.A., Addo, A.A., Sonibare, M.A. (2004). Activity pattern, energy intake and obesity among Nigerian urban market women. Int. J. Food Sci. Nutr., 55(2), 85-90.

Akinloye, T.E. (2010). Food consumption pattern, lifestyle and body mass index of market women (a case study of IkosiIsheri Local Government area of Lagos State, Nigeria. Unpublished BSc Thesis). University of Agriculture, Abeokuta.

Araoye, M.O. (2003). Research methodology with statistics for health and social sciences. Nathadex Publishers, Nigeria, pp117-119.

Awosan, K. J., Ibrahim, M. T. O., Essien, E., Yusuf, A. A. \& Okolo, A.C. (2014). Dietary pattern, lifestyle, nutrition status and prevalence of hypertension among traders in Sokoto Central market, Sokoto, Nigeria. International Journal of Nutrition and Metabolism, 6(1), 9-17.

Balogun, M.O. \& Owoaje, E.T. (2007). Work condition and health problems of female traders in Ibadan, Nigeria. Afr J Med Med Sci., 36 (1), 57-63.

FAO/WHO. (1992). Improving household food security. $A$ theme paper prepared for the International Conference on Nutrition. PREPCOM/ICN/92/INF/6. Rome, Food and Agriculture Organization.

Ganasegeran, K., Al-Dubai, S.A,, Qurechi, A.M, Al-Abed, A.A, An, R. \& Aljunaid, S.M (2012). Social and psychological factors affecting eating habits among university students in a Malaysian medical school: a cross sectional study. Nutr. J., 11:48.

Harrison, K.A., Rossiter, C.E. \& Chong, H. (1985). Relations between maternal height, fetal birth weight and cephalopelvic disproportion suggest that young Nigerian primigravidae grow during pregnancy. BrJ Obstet Gynaecol., Suppl $5,40-48$
Mebude, A.S. (2010). Prevalence of obesity among market women in Abeokuta. (Unpublished BSc Thesis). University of Agriculture, Abeokuta.

Ming, M.F., Ying, G.C. \& Kassim, S.Z.M. (2006). Eating patterns of school children and adolescents in Kuala Lumpur. Mal J Nutr., 12, 1-10.

Odugbemi, T.O., Onajole, A.T. \& Osibogun, A.O. (2012). Prevalence of cardiovascular risk factors amongst traders in an urban market in Lagos, Nigeria. Niger Postgrad Med., 19(1), 1-6.

Ojo, J.O., Oketayo, O.O., Aboderin, A.O., Salawu, A.A. \& Adewusi, S.R.A. (2011). Evaluation of nutritional status using body fat, physiological and biochemical parameters in some Nigerian women. Nutrition and Health, 20: $197-208$.

Okafor, P.N., Ukegbu, P.O., Godfrey, O.C., Ofoegbu, M.C. \& Uwaegbute, A.C. (2014). Assessment of lipid profile in middle and upper class individuals in Abia State, Nigeria based on life-style and dietary habits. Journal of Medical and Biomedical Sciences (2014) 3(3): 1-8.

Oladoyinbo, C.A., Ekerette, N.N. and Ogunubi, T.I. (2015). Obesity and Hypertension amongst Traders in Ijebu Ode, Nigeria. Afr. J. Biomed. Res.,18(1):23-27

Oniang'O, R.K., Mutuku, J.M. \& Malaba, S.J. (2003). Contemporary African food habits and their nutritional and health implications. Asia Pacific J Clin Nutr., 12 (3): 231-236.

Piernas, C. \& Popkin, B. (2010). Snacking increased among U.S. adults between 1977 and 2006. Journal of Nutrition, 140(2), 325-332.

Poulain, J. (2002). The contemporary diet in France: 'Destructuration from commensalism to 'vagabond feeding'. Appetite, 39,43-55.

Ukegbu, P.O. (2014). A study of the nutritional status and dietary intake of lactating women in Umuahia, Nigeria. American Journal of Health Research, 2(1), 20-26

WHO (1995). Physical status: The use and interpretation of anthropometry. Who Technical Report Series. 854, pp. 375-409.

WHO (2000). Obesity: Preventing and managing the global epidemics: Report of a WHO Consultation Technical Report Series No 894, WHO Geneva, 2000.

WHO. (2010). Obesity and overweight. Retrieved from www. who.intldietphysicalactivity/publications/facts/obesity/ en/ (accessed 3/05/13).

World Bank. (1992). World Bank Africa Technical Department. Better health in Africa. Washington, DC: World Bank. 